\title{
Pregnancy outcome in low risk pregnancy with decreased amniotic fluid index
}

\author{
Swathi Bhat*, Ambika H. E., Lepakshi B. G., Savitha C. S.
}

Department of Obstetrics and Gynecology, Shimoga Institute of Medical Sciences, Shimoga, Karnataka, India

Received: 27 January 2017

Accepted: 14 February 2017

\author{
*Correspondence: \\ Dr. Swathi Bhat, \\ E-mail: swathinandakishore@gmail.com
}

Copyright: (c) the author(s), publisher and licensee Medip Academy. This is an open-access article distributed under the terms of the Creative Commons Attribution Non-Commercial License, which permits unrestricted non-commercial use, distribution, and reproduction in any medium, provided the original work is properly cited.

\begin{abstract}
Background: To evaluate whether oligohydramnios $(\mathrm{AFI} \leq 5)$ has any significance in the outcome of low risk pregnancies. Normal amniotic fluid index in pregnancy is one of the indicators of fetal well-being. In a term pregnancy, oligohydramnios, a condition associated with $\mathrm{AFI} \leq 5$, could be a sign of placental insufficiency. An association of low AFI with complications like pregnancy induced hypertension, consistently leads to poor fetal outcome. A need to deliver the fetus by cesarean section often arises. Occasionally one comes across a full-term pregnancy with AFI $\leq 5$ with no known high risk factors; this could lead to increased cesarean section rates. Thus, it becomes necessary to evaluate if AFI $\leq 5$ in the absence of other risk factors has any significance on obstetric outcome.

Methods: Prospective case controlled study was done. Fifty women with term pregnancies and $(A F I \leq 5) \mathrm{cm}$ not associated with any other high risk factors were enrolled for the study. They were matched with fifty controls with normal AFI.

Results: Except for a slight increase in variable deceleration in the study group, no differences were noted with fetal heart rate recordings in NST. Decreased AFI was not associated with increased cesarean section rates, instrumental deliveries or meconium stained amniotic fluid. Severe asphyxia, NICU admission or perinatal mortality was not noted in either group.

Conclusions: When a low risk pregnancy is associated with Oligohydramnios (AFI $\leq 5)$, it does not have any deleterious effect on labor outcome or perinatal outcome.
\end{abstract}

Keywords: AFI, Labor outcome, Low risk pregnancy

\section{INTRODUCTION}

Amniotic fluid index is calculated by adding the vertical depth of the largest pocket in each of the four equal uterine quadrants. ${ }^{1}$ Amniotic fluid index of $\leq 5$ could be as a result of placental insufficiency or due to decreased fetal urine production. There could be cord compression and in turn fetal distress with increased cesarean section rates. ${ }^{2}$ An association of low AFI with complications like pregnancy induced hypertension, consistently leads to poor fetal outcome. A need to deliver the fetus by cesarean section often arises. ${ }^{3}$ Occasionally one comes across a full-term pregnancy with AFI $\leq 5$ with no known high risk factors; this could lead to increased cesarean section rates. ${ }^{4}$

Thus, it becomes necessary to evaluate if AFI $\leq 5$ in the absence of other risk factors has any significance on obstetric outcome.

\section{METHODS}

A prospective study was conducted over $1 \frac{1 / 2}{2}$ years from January 2014 to June 2015. All singleton term pregnancies with a single fetus, with AFI of 5, with intact membranes at the time of admission were included. 
Anomalous baby, previous bad obstetric history, previous perinatal loss, previous cesarean section, post term pregnancy, evidence of growth retardation and medical disorders like pregnancy induced hypertension, anemia, diabetes, heart diseases were excluded. An admission NST was done in all cases.

The controls were subjects with AFI $>5$ but $<20$. Both groups were matched for maternal age, parity, gestational age and hemoglobin levels. The same team monitored the progress of labor and conducted delivery of both the groups.

Outcomes with respect to the following were assessed:

NST changes during labor, need for cesarean section due to NST changes, meconium stained amniotic fluid, APGAR score of the neonate, NICU admission, perinatal mortality and morbidity. The outcomes were recorded and statistically analyzed.

\section{RESULTS}

A total of 50 women with $\mathrm{AFI} \leq 5 \mathrm{~cm}$, with low risk pregnancies were considered. These women were matched with 50 women whose AFI was more than 5 but less than 20 .

Table 1: Fetal heart rate patterns.

\begin{tabular}{|llll|}
\hline & $\begin{array}{l}\text { AFI } \\
5 \mathrm{CM}\end{array}$ & $\begin{array}{l}\text { AFI } \\
\geq 5 \mathrm{CM}\end{array}$ & P value \\
\hline $\begin{array}{l}\text { Normal basal heart } \\
\text { rate (110-160) }\end{array}$ & 49 & 48 & 0.31 \\
\hline $\begin{array}{l}\text { Beat to beat } \\
\text { variability }\end{array}$ & 47 & 48 & 0.17 \\
\hline $\begin{array}{l}\text { Accelerations }>15 \\
\text { beats per minute }\end{array}$ & 46 & 47 & 0.5 \\
\hline Late deceleration & 01 & 00 & $\mathrm{NA}$ \\
\hline Variable declarations & 06 & 01 & 0.05 \\
\hline
\end{tabular}

Table 1 shows that there is no statistical difference between the two groups with respect to fetal heart rate abnormalities. A small increase in variable deceleration was noted in the group with AFI $\leq 5$ but this is not statistically significant.

Table 2: Mode of delivery.

\begin{tabular}{|llll|}
\hline Mode of delivery & AFI & AFI & P value \\
\hline $\begin{array}{l}\text { Lower segment cesarean } \\
\text { section }\end{array}$ & 9 & 10 & 0.81 \\
\hline $\begin{array}{l}\text { Instrumental vaginal } \\
\text { delivery }\end{array}$ & 4 & 4 & $\mathrm{Na}$ \\
\hline Normal vaginal delivery & 37 & 36 & 0.83 \\
\hline
\end{tabular}

There is no significant difference in cesarean section in the two groups. Instrumental vaginal delivery with vacuum extractor and forceps delivery was the same in both the groups.

Table 3: Indication for LSCS.

\begin{tabular}{|lll|}
\hline Indication & $\begin{array}{l}\text { AFI } \\
\leq 5 \mathrm{CM}\end{array}$ & $\begin{array}{l}\text { AFI } \\
\geq 5 \mathrm{CM}\end{array}$ \\
\hline Abnormal heart rate pattern & 02 & 01 \\
\hline Non-progression of labor & 04 & 05 \\
\hline CPD & 01 & 02 \\
\hline Meconium stained liquor & 02 & 02 \\
\hline
\end{tabular}

Four babies in the study group had an APGAR score of less than 7 at 5 minutes, while only 2 babies in the control group had similar APGAR. All the babies were resuscitated easily by bag and mask. No baby either in the study or the control groups had APGAR $\leq 4$, that is no baby was severely asphyxiated. NICU admission was nil. No perinatal mortality was seen in either of the groups. The mean birth weight of the babies in the study group was $2480 \pm 120 \mathrm{~g}$ and in the control group it was $2770 \pm 150 \mathrm{~g}$.

\section{DISCUSSION}

Reduced amniotic fluid at term is generally considered to have increased risk of intrapartum complications. ${ }^{5}$ The risk is further compounded in high risk pregnancies. ${ }^{6}$ However the quantum of risk with reduced amniotic fluid is less clear in low risk pregnancies. Studies have given conflicting results. ${ }^{7,8}$ Reduced AFI in low risk pregnancies that is isolated reduction in amniotic fluid in the presence of intact membranes and with no other risk factors is not a common finding. Only 50 cases were registered in a period of $11 / 2$ years in a hospital with 600-700 deliveries a month. Few other similar studies are reported. ${ }^{9-11}$

Variable deceleration is known to occur as a result of cord compression during labor. A slight increase in variable decelerations was a noted in women with low AFI but this was not statistically significant and it did not increase cesarean section rates.

Outcome with respect to the fetus in women with low AFI was comparable to the groups with normal AFI. The APGAR scores were comparable, none of the newborns needed admission to NICU. There was no perinatal mortality in the study group. One study reported a small but insignificant increase in low APGAR score at $5 \mathrm{~min}$ when AFI <5. ${ }^{10}$ Meconium stained liquor with its complications in the neonatal period is considered as an indication of fetal distress but in the present study AFI $\leq 5$ was was not associated with increased incidence of meconium stained liquor. 


\section{CONCLUSION}

Reduced AFI in low risk term pregnancies may have no adverse effect on labor and perinatal outcome. The present study indicates that an isolated finding of decreased AFI in the absence of any other Obstetric risk factor, does not cause fetal jeopardy. Hence a finding of Oligohydramnios in an otherwise low risk pregnancy need not be an indication for cesarean section.

\section{ACKNOWLEDGMENTS}

The authors extend their heartfelt thanks to the College Director, all the Doctors, nursing staff, office personnel of the Department of Obstetrics and Gynecology, Shimoga Institute of Medical Sciences, Shimoga, Karnataka, India, for their co-operation.

\section{Funding: No funding sources}

Conflict of interest: None declared

Ethical approval: Not required

\section{REFERENCES}

1. Phelan and colleagues. Quantification using amniotic fluid index. In: Cunningham, Mac Donald, Gant, Leveno, Gilstrap, Hankings et al eds. William Obstetrics $20^{\text {th }}$ Edition Prentice-Hall International, Inc; 1997:659.

2. Grubb DK, Paul RH. Amniotic fluid index and prolonged antepartum fetal heart rate decelerations. Obstet Gynecol. 1992;79(4):558-60.

3. Sarno and co-workers. Intrapartum amniotic fluid at term. J Rep Med. 1990;35:719.

4. Chauhan SP, Washburne JF, Magann EF, Perry KG Jr, Martin JN Jr, Morrison JC. A randomised study to assess the efficacy of the AFI as fetal admission test. Obstet. Gynecol. 1995;86:9.

5. Groome LJ, Owen J, Neely CL, Hauth JC. Oligohydramnios and intrapartum fetal distress. In: Cunningham, Mac Donald, Gant, Leveno, Gilstrap, Hankings et al eds. William Obstetrics $20^{\text {th }}$ Edition Prentice-Hall International, Inc. 1997:665.

6. Magann EF, Kinsella MJ, Chauhan SP, McNamara MF, Gehring BW, Morrison JC. Does AFI <5 necessitate delivery in high risk pregnancies? A case controlled study. Am J Obstet Gynaecol. 1999:180:1354-9.

7. Ghosh G, Marsa' KL, Gudmundsson S. AFI in low risk pregnancy as an admission test to labor ward Acta Obstet, Gynecol Scand. 2002,81:852-5.

8. Nyles TD, Santolaya Forgan J. Ultrasonic evaluation of amniotic fluid in low risk patients at term. J. Reprod. Med. 2002;47:621-4.

9. Morris JM1, Thompson K, Smithey J, Gaffney G, Cooke I, Chamberlain $\mathrm{P}$, et al. The usefulness of ultrasound assessment of amniotic fluid in predicting adverse outcome in prolonged pregnancies. BJOG. 2003;110:989-94.

10. Kriser D, El Sayed YY Sorem KA. Decreased amniotic fluid index in low risk pregnancy. J Reprod Med. 2001;46:743-6.

11. Jun Zhanga J, James Troendlea J, Susan Meikleb S, Klebanoffa MA, Rayburn WF. Isolated oligohydramnios is not associated with adverse perinatal outcome. BJOG. 2009;111:220-5.

Cite this article as: Bhat $\mathrm{S}$, Ambika HE, Lepakshi BG, Savitha CS. Pregnancy outcome in low risk pregnancy with decreased amniotic fluid index. Int $\mathrm{J}$ Reprod Contracept Obstet Gynecol 2017;6:887-9. 